\title{
El pluralismo jurídico en América Latina y la nueva fase del colonialismo jurídico en los estados constitucionales
}

Legal pluralism in Latin America and the new phase of legal colonialism in constitutional states

Rosembert Ariza Santamaría

Resumen: En Latinoamérica en las últimas tres décadas el tema del pluralismo jurídico se revitalizó a partir de múltiples reformas constitucionales y de diferentes procesos constitucionales. Sin desconocer este contexto y a partir de algunas reflexiones teóricas de gran acogida en América Latina, se ausculta este tema de crucial importancia para el derecho contemporáneo intentando revisar el alcance de estas propuestas en los Estados latinoamericanos en sus diferentes procesos de desarrollo constitucional y en segundo lugar mirar para dónde va el pluralismo y en esa mirada interpelar a los doctrinantes, juristas y operadores judiciales que en América Latina proponen caminos para este tema.

Palabras claves: Pluralismo, colonialismo jurídico, descolonización, Estados constitucionales, Estados en transición

Abstract: In the last three decades, in Latin America, the topic of legal pluralism is revitalized from multiple different constitutional reforms and constitutional processes. Without ignoring this context and from some theoretical reflections of great success in Latin America, this issue of crucial importance for the contemporary law is heard trying to revise

1 Abogado, Doctor en sociología jurídica, docente investigador Universidad Nacional de Colombia, miembro del grupo de investigación Estado, sociedad y pluralismos, miembro de Prujula, Relaju y de la red de constitucionalismo democrático de Latinoamérica. 
the scope of these proposals in Latin American states in their different processes of constitutional development and secondly, to know where pluralism is going and, from there, interpellate the authors, lawyers and judicial operators in Latin America that propose ways for this.

Keywords: Pluralism, Legal colonialism, decolonization, constitutional states, states in transition

Considero que el pluralismo jurídico intercultural es la capacidad de comprensión sin pretensión de fusión entre sistemas jurídicos, practicas jurídicas y formas de convivencia regladas, sin orden jerárquico ni sometimiento racional de unos a otros.

Tal vez parto de un falso dilema al asumir que estoy en posición de una idea de pluralismo progresista, o lo hago solo para señalar que existe un pluralismo conservador o un pluralismo que es parte del monismo clásico legal positivista como los señala acertadamente el profesor Brasilero Antonio Carlos Wolkmer.

Asumo que mi noción de pluralismo es más amplia y "progresista" por deslindarme de los herederos de Savigny lo que el profesor Portugués Antonio Manuel Hespahna llama los nietos de Savigny, y desde su bucólica interpretación de la historia del derecho demuestra que el debate monismo pluralismo es un viejo debate de la edad media aun sin concluir y destaca el profesor que el monismo no es tan prestigioso como se presume ni siquiera en los Estados más absolutos, pues siempre se ha reconocido otros ordenes legales (2010, p. 142); igual Tamanaha no duda en aseverar que "parecería que los pluralistas jurídicos han creado un oponente temible y hegemónico - el monismo jurídico - para inflar la importancia de su concepción del pluralismo jurídico" (2007, p. 227 ).

Pero tampoco se puede pecar de optimismo crónico para creer que el pluralismo jurídico es la receta para la consolidación de un derecho democrático e incluyente capaz de producir trasformaciones societales en pro de los excluidos de siempre.

Un pluralismo jurídico que logre la integración entre distintos órdenes normativos de sociedades plurales es una quimera pero su inte- 
gración sin fusión es el paso inicial de un Estado plurinacional, una tarea de construcción que requiere replantear toda la base conceptual y racional del propio derecho, en esta tarea se encuentra la unidad de descolonización del tribunal constitucional plurinacional de Bolivia, quienes silenciosamente en los dos últimos años trabajan para encontrar claves que les permitan materializar esta idea ajena al derecho racional que solo admite la subordinación como regla de comprensión frente a distintos y diferenciados ordenes normativas o sociales.

Pretender prácticas jurídicas y formas de convivencia regladas, sin orden jerárquico ni sometimiento racional de unos a otros es un ejercicio hermenéutico profundamente complejo que requiere despojarse de la prepotencia racional legal y de la supremacía jurídica a los detentadores del discurso formal del derecho occidental.

Esta línea de pluralismo es señalada textualmente por la Constitución Boliviana: Art.179.II. La jurisdicción ordinaria y la jurisdicción indígena originario campesina gozarán de igual jerarquía.

El Tribunal Constitucional Plurinacional en cumplimiento de esta tarea ha dado pasos adelante y atrás con el derecho que les asiste de equivocarse, pues aquí la igualdad predicada no es la de la tradición jurídica occidental sino la de la comprensión andina.

El gobierno boliviano se equivocó con la inaplicada ley de deslinde jurisdiccional y el Tribunal Constitucional Plurinacional se equivocó con el caso del Tipnis, pero hay múltiples aciertos que señalan el camino a los sueños de un pluralismo jurídico descolonizador.

Frente al Pluralismo jurídico colonial del Estado constitucional este tiene una línea histórica de olvidos que según define Idón Moisés Chivi Vargas es: la amnesia del derecho moderno que estriba en un olvido histórico, en el olvido de su origen. Y es que el Estado y el Derecho "modernos" le deben su existencia a un acto colonial y terriblemente dramático: El genocidio de las indias ayer y hoy. El genocidio primero, el del colonialismo español encuentra su envase normativo en una pieza de arqueología jurídica: la Recopilación de las Leyes de Indias. El genocidio segundo: el liberal vino ya con envase de derechos, vino en Constitución y Códigos y... se quedó. Evadiendo e ignorando el geno- 
cidio primero, la globalización del derecho ha tratado de poner frenos a los procesos emancipatorios que hoy se abren por toda América Latina.

Sigue señalando Idón Chivi que en América Latina, después de 30 años de reforma jurídica y judicial, ponen en evidencia el gran problema de nuestros sistemas judiciales: su pesada herencia colonial. Una herencia, que no debe ser entendida ni confundida con la reproducción simple de mecanismos coloniales, sean estos institucionales y organizacionales, que para el caso da lo mismo, sino más bien como dispositivos excesivamente complejos y que encubren la colonialidad (CHIVI, 2009).

El professor brasileño Antônio Carlos Wolkemer señala de manera muy pertinente en el debate académico:

A hipótese nuclear da proposta é a de que a ineficácia do modelo de legalidade liberal-individualista favorece, na atualidade, toda uma ampla discussão para se repensar os fundamentos, o objeto e as fontes de produção jurídica. Ademais, a condição primeira para a materialidade efetiva de um processo de mudança, em sociedades emergentes, instáveis e conflituosas implica, necessariamente, a reorganização democrática da sociedade civil, a transformação do Estado Nacional e a redefinição de uma ordem normativa identificada com as carências e as necessidades cotidianas de novos sujeitos coletivos. Para além das formas jurídicas, positivas e dogmaticamente instituídas, herdadas do processo de colonização, torna-se imperioso reconhecer a existência de outras manifestações normativas informais, não derivadas dos canais estatais, mas emergentes de lutas, conflitos e das flutuações de um processo histórico-social participativo em constante reafirmação. (2006, p. 72)

El presente análisis pretende repensarse los fundamentos de la producción jurídica por fuera de la matriz eurocéntrica del colonialismo jurídico occidental, y constatar los alcances del modelo transicional del Estado plurinacional Boliviano, junto a las referencias anteriores muchos son los estudiosos del pluralismo que proponen un pluralismo intercultural, sin superar las simples disquisiciones teóricas, sin dejarlas de lado miraremos si en la actual fase del llamado Estado constitucional se sigue reproduciendo el llamado colonialismo jurídico o es posible un ejercicio descolonizador en el campo constitucional. 


\section{LA RECONFIGURACIÓN DEL ESTADO}

Asistimos a trasmutaciones y cambios de las nociones clásicas de Estado Nación, del llamado Estado de derecho y a la propuesta del Estado constitucional, en tiempos del Estado plurinacional, en últimas a la reconfiguración del Estado. El pluralismo y la plurinacionalidad son elementos determinantes en tales trasformaciones que como ya se dijo en las últimas décadas determinan condiciones de posibilidad de un modelo de Estado más ajustado a las realidades nacionales.

La noción de Estado constitucional que nos referimos es la formulada por el profesor Rubén Martínez Dalmau, quien señala una indisoluble asimilación entre pueblo, poder constituyente y soberanía, que conforman los cimientos de la Constitución democrática; al mismo tiempo, el texto constitucional consagra los elementos de la garantía y desarrollo del gobierno democrático, lo que da paso al Estado constitucional. La elección y el control efectivo de los gobernantes por parte del soberano y su autolimitación a través del Derecho constituyen, de esta manera, el elemento primordial para la entrada en vigor del principio democrático y, con ello, la aparición de la Constitución material -democrática-, principal característica del Estado constitucional (2012, p. 8).

Esta constitución material democrática es impensable sin unos desarrollos en materia de pluralismo y pluralismos, el punto es cuánto de esto encuadra en lo que asumiríamos como colonialismo jurídico en particular la autolimitación a través del Derecho, pues si hay un dispositivo de carácter colonial es el derecho mismo, y darle este lugar no permite ninguna trasformación real del modelo de Estado y de la posibilidad de otro modo jurídico que supere la idea occidental de lo legal frente a lo legítimo.

De otro lado el Boliviano Raúl Prada lee el tema desde la eterna crisis del Estado: Se puede decir que los Estado-nación se mueven en un intervalo de opciones que se circunscriben a administrar la crisis. La salida a la crisis estructural del capitalismo sólo se puede dar a escala mundial, esta superación de la crisis del capitalismo solo se puede dar ingresando a un nuevo horizonte histórico y cultural, un horizonte que se sitúa en otro espacio-tiempo, que se encuentra más allá 
del mundo capitalista, más allá del mundo moderno. Mientras tanto, en este encaminarse, en la transición a un postcapitalismo, se hace necesario preparar el terreno, crear las condiciones para la superación del capitalismo. Para el transcurso de esta transición transformadora es menester la imaginación y lo imaginario radicales, su potencia creativa, además de la fuerza instituyente. (2010, p. 80)

Esta perspectiva nos fija un horizonte más allá de lo que pretende clásicamente un estado convencional, establece un proyecto de sociedad sin capitalismo tan pertinente cuanto necesario es una sociedad sin colonialismo.

El propio Prada recuerda -algo que se dijo durante la Asamblea Constituyente- se requiere un nuevo mapa institucional, pero también se requiere un nuevo imaginario social. Ambos ámbitos, lo imaginario y lo institucional, requieren de una conexión simbólica. En resumen, estos tres ámbitos, lo imaginario, lo simbólico y lo institucional hacen al horizonte histórico cultural; en ese sentido, un nuevo horizonte histórico y cultural se abre cuando se dan transformaciones imaginarias, transformaciones simbólicas y transformaciones institucionales. (2010, p. 80)

Estas transformaciones institucionales las encarna el propio Tribunal Constitucional Plurinacional de Bolivia y su Unidad de descolonización que apuestan a imaginar posibles interculturales que desafían al derecho hegemónico permanentemente y que suscita airadas conspiraciones por los juristas del modelo colonial.

El Pluralismo en el Derecho demuestra que el poder estatal no es la fuente única y exclusiva de todo el Derecho, abriendo espacio para una producción y aplicación normativa, centrada en la fuerza y la legitimidad de un complejo y difuso sistema de poderes, emanados dialécticamente de la sociedad, de sus diversos sujetos, grupos sociales, colectividades o cuerpos intermedios, como la afirma el profesor Wolkmer.

Sin entrar en una discusión sobre las variantes del Pluralismo jurídico, ya sea sobre el paradigma "desde arriba", transnacional y globalizado o del modelo "desde abajo", de las prácticas sociales emancipadoras y de los movimientos sociales, es importante subrayar la proposición de un constitucionalismo pluralista y emancipador. A partir 
de ahí, aparece la aproximación e integración entre la constitución y el Pluralismo democrático, proyectando la perspectiva de un nuevo Estado de Derecho, y una constitución que consagre y reafirme al Pluralismo como uno de sus principios fundamentales, determinando no sólo un modelo de Estado Pluridimensional, sino que específicamente, un proyecto para una sociedad intercultural.

Desde este planteamiento sugerente del profesor Antonio Carlos podemos preguntarnos si es posible "otro" Estado de derecho o un nuevo Estado que garantice una sociedad intercultural, cuando la matriz jurídico política del Estado de derecho es mono cultural, monista y por construcción política excluyente y de clara estirpe colonial.

Nos queda recogernos en el horizonte del Estado plurinacional Boliviano como materialización de una constitución democrática que responde a un proyecto intercultural que en el actual momento se predica en transición y cuya apuesta central es la descolonización de la sociedad. Lograr tal cometido implica décadas de trabajo y un profundo cambio de las instituciones políticas, sociales y sobre todo de las jurídicas.

En la investigación sobre Justicia Indígena, Plurinacionalidad e interculturalidad en Ecuador y Bolivia el profesor Baoventura sostiene que el multiculturalismo liberal reconoce la presencia en la sociedad de culturas no eurocéntricas en la medida en que operen únicamente en las comunidades que las adoptan y no interfieran en la cultura dominante en el resto de la sociedad. No es este el multiculturalismo consagrado en las constituciones de Bolivia y Ecuador. El nuevo Estado plurinacional emergente y su componente intercultural no exige simplemente un reconocimiento de la diversidad, sino más bien la celebración de la diversidad cultural y el enriquecimiento recíproco entre las varias culturas en presencia (2012, p. 22).

Sin embargo este si es el multiculturalismo vigente en países como Colombia que lograron llevar el multiculturalismo a toda su plenitud, con el agravante que Colombia es el ejemplo a seguir en la mayor parte de Estados latinoamericanos.

Según el profesor Boaventura la dificultad de reconocer y valorar la diversidad intercultural tiene un nombre viejo pero igualmente válido: 
se llama colonialismo. El colonialismo es todo sistema de naturalización de las relaciones de dominación y de subordinación basadas en diferencias étnicas o raciales. El Estado moderno es monocultural y es colonial en ese sentido, porque sus instituciones siempre han vivido a partir de una norma, que es una norma eurocéntrica que no celebra sino, al contrario, oculta la diversidad.

Coincidiendo con este planteamiento el Estado o los Estados en Latinoamérica avanzan hasta la diversidad y hacen de ella el nicho de desarrollo del juricidismo y las prácticas modernas del derecho. Trae importantes réditos tal "inclusión" gramatical en la retórica jurídica que no pone en entre dicho el "contrato" ni la seguridad jurídica.

El colonialismo jurídico sigue permeando las reformas constitucionales y las pretensiones de cambio de los Estados y por muy profundo que sean los cambios constitucionales el derecho no muta solo se reconfigura en otra nueva forma en la nueva fase y cambia simplemente su nomenclatura de Estado de Derecho a Estado constitucional, sin resolver los problemas históricos y las deudas pendientes en materia de sociedades y nacionalidades excluidas del poder.

En una reciente investigación comparativa México-Guatemala las profesoras María Teresa Sierra, Rosalva Hernandez y Rachel Sieder indagan las justicias indígenas el Estado y las violencias contemporáneas y plantean tres direcciones del tema, a) La trasformación del campo jurídico y las nuevas configuraciones del Estado neoliberal b) la disputa por la justicia indígena y comunitaria desde los márgenes del Estado; c) la politización de las identidades y el reclamo de los derechos.

En palabras de las profesoras la reforma constitucional mexicana del año 2001 acerca de los derechos indígenas no reconoció territorios ni jurisdicciones indígenas. Y en Guatemala, los compromisos del Estado para reconocer los derechos indígenas nunca se tradujeron en una reforma a la constitución de 1985 (2013, p. 23-24) y ellas aclaran que al decretar la atención específica a los pueblos indígenas, las políticas y los programas multiculturales impulsados después de la guerra en Guatemala significaron una ruptura con el pasado. Cosa que contrasta con México, donde de alguna forma, hubo cierta continuidad en 
las políticas indigenistas o "neoindigenistas" después de la reforma constitucional de 2001.

En México, los lineamientos constitucionales de 2001 delimitaron el alcance de las reformas en materia de justicia, que se redujeron a reconocer los sistemas normativos internos de las comunidades indígenas y a establecer ciertas garantías para el acceso a la justicia del Estado, como reconocer costumbres y especificidades culturales en el proceso judicial, así como el derecho a intérpretes y traductores, agregan las investigadoras del ciesas.

Y como ya fue dicho en el caso de Guatemala poco se hizo desde el Estado y le correspondió a la cooperación internacional el papel de impulsar estas otras justicias, llegando a un modelo híbrido de "juzgados de paz comunitarios" sin reconocer de manera concreta las demandas de reconocimiento legal y autonomía jurisdiccional de los pueblos indígenas.

Las autoras además logran constatar una transición del Estado multicultural neoliberal a un Estado penal, que es el caso de México en los últimos años y en paralelo revisan el Estado como efecto donde revisan la construcción discursiva, los imaginarios y las representaciones de distintas regiones donde en efecto se dan distintos encuentros y desencuentros entre los pueblos indígenas con sus prácticas materiales y discursivas. Encuentran además que un rasgo distintivo de las experiencias analizadas y subordinadas al Estado en las que se pone en juego el modelo de justicias alternativas, es justamente el proceso de oficialización de la justicia indígena y su impacto en la construcción y el significado de la autoridad y el derecho indígena. Dichos proceso responden según las autoras citando a Hale, a la doble lógica del multiculturalismo neoliberal, por un lado está el reconocimiento acotado de derechos culturales, y por el otro, se encuentra el impacto sobre las categorías étnicas y sus efectos diferenciadores en la autoridad indígena.

Con esta investigación se prueba como las reformas multiculturales de nuevo cuño logran trasformar el concepto "indígena" y llevarlo de lo analítico legal a la idea de auto adscripción haciendo nuevas rupturas en las identidades indígenas no sin intención. 
Estamos sin duda en un momento de fortalecimiento del multiculturalismo y no en un "después del multiculturalismo" las diferentes reformas que otros Estados diferentes al Mexicano y Guatemalteco han caminado en esta última década nos permite entrever como se consolida este modelo en los Estados latinoamericanos, y en las reformas constitucionales que están por venir en Chile, Brasil, Perú y la propia Colombia tiene como techo este modelo que el mundo jurídico encuentra políticamente correcto y que los juristas constitucionalistas conservadores ven como el más pertinente.

\section{UN DERECHO COLONIAL, UN DERECHO PROPIO, UN NUEVO DERECHO: EL PLURALISMO DE SIEMPRE}

Un referente común es el derecho europeo como derecho dominante en América Latina, sin desconocer que el derecho norteamericano se constituye en el derecho global hegemónico y ellos en simultaneo operan en un continente multiétnico, multicultural y plurilingüe que con cinco siglos de colonialismo hoy reconoce derechos específicos a los pueblos indígenas y afrodescendientes, herederos de civilizaciones que existían previamente a la colonización europea que definió el rumbo de nuestra historia moderna. Así mismo, en diferentes etapas históricas de nuestros países se han venido reconociendo un conjunto de derechos civiles, políticos, económicos, sociales, ambientales y culturales que reflejan demandas y aspiraciones de equidad, buen vivir, vida buena y una mejor convivencia de estas sociedades plurales.

Salvo Bolivia ningún Estado reconoce el pluralismo jurídico igualitario real, los Estados a distintos ritmos conforme a sus propias precariedades legales avanzan muy poco en esta materia, revisando el conjunto de países se podría asegurar prima fase que estamos en el pluralismo de siempre, el de la colonia con nuevos ropajes y nuevos profetas que reivindican una noción de civilización moderna sin percatarse de la pluridiversidad y de la existencia de sociedades diferentes en su Estados. 
El reconocer sociedades que tienen órdenes sociales y jurídicos diferentes al sistema jurídico hegemónico dentro de un Estado es una de las expresiones del pluralismo, sin embargo se circunscribe en la mayor parte de los casos solo a eso a "reconocerlos" sin mayor garantía que la garantía de su reconocimiento.

En el modelo de garantismo jurídico que cobija gran parte de los sistemas jurídicos de los Estados latinoamericanos que se denominan constitucionales, el pluralismo es desarrollado en el entendido de dicho modelo que pretende ser un nuevo derecho cuya base es el mismo positivismo jurídico.

Manuel Jacques convoca a preguntarse dónde se sitúan los "teatros de conflictividad jurídica" en que se desenvuelve la nueva normatividad, quiénes se confrontan en ellos y cómo lo hacen, y cuál es el carácter de esa confrontación, que está dada precisamente

por estos escenarios de constelaciones jurídicas que están interactuando: una constelación de carácter supraestatal -con discurso regulatorio, con espacios de construcciones normativizadas, pero también de prácticas comerciales que han determinado un nuevo orden económico y social-y también esta constelación de prácticas socio comunitarias que reclaman su propio proceso de afirmación de identidades (GTZ, 2010).

La inclusión de las sociedades, pueblos y nacionalidades excluidas históricamente en Latinoamérica solo es parte del problema y no es todo, pues la retórica legal liberal en parte resolvió este tema con los discursos multiculturales, repertorio que se agotó en sí mismo en el actual modelo de Estado, queda avanzar a una interculturalidad real que inicia con la superación del colonialismo jurídico.

\section{MULTICULTURALISMOS/INTERCULTURALIDAD CONSTITUCIONAL}

El multiculturalismo se encarna en América Latina a comienzos de los noventas en gran parte de los Estados con una formula común, la 
del denominado "reconocimiento", de este primer momento a la idea actual de interculturalización se ha fijado diferentes comprensiones acerca de la diversidad, la diferencia, lo racial y lo étnico.

Pero el modelo que más desarrollo tiene en los Estados latinoamericanos en materia de multiculturalismo es sin duda el Colombiano al punto que su constitucionalismo es reconocido por la propia Corte Constitucional y la doctrina como el constitucionalismo multicultural

En el desarrollo de este constitucionalismo se dan tres etapas, la primera del multiculturalismo limitante donde es evidente la ausencia de diálogo "multicultural". Esta perspectiva es revisada un estudio de varias sentencias de la Corte Constitucional, el profesor Ariza crítica los bandazos que se observan en este primer momento del constitucionalismo, producto quizás del desconocimiento de dichas culturas que se evidencia de manera notoria, tanto que incluso llega a un campo en que limita, antes que establecer límites de actuación:

En este análisis vale la pena entonces analizar cómo lo realizado por la corte en una primera etapa es un desborde de los límites y si ésta cae irremediablemente en las llamadas limitaciones, que, por el contrario del límite, no derivan ni son consecuencia directa de la naturaleza y estructura de los derechos fundamentales sino de la regulación concreta que se haga de los mismos (2010, p. 98).

Por ello, este autor se inclina por sostener que las reglas de juego sobre el funcionamiento de la justicia indígena no sean establecidas desde las instituciones, sino desde un diálogo intercultural que involucre las consultas debidas a los pueblos concernidos (2010, p. 107).

Otro autor colombiano en la misma línea señala que esta tensión se encuentra también, en las sentencias de la Corte Constitucional, especialmente las que buscan resolver la tensión entre unidad y diversidad cultural en casos que afectan comunidades indígenas. Sin que existan posiciones definidas, por ello Daniel Bonilla ilustra sobre tres tipos de sentencias distintas adoptadas por la Corte (las de tipo liberal propiamente, las multiculturales e incluso algunas de tipo intercultural, que 
dan prelación a la protección de los valores liberales), la justificación que se esgrime para la protección de la diversidad propia sigue siendo inconsistente y, por ende, insatisfactoria

Pero la pluralidad de valores y estilos de vida resulta un lugar común. Y aquí es donde aparece el valor del multiculturalismo, que exigiría que todas las comunidades constitutivas de una sociedad se toleren entre sí. Pero este valor no está dado por la cultura en sí, sino por el tinte de las sociedades liberales:

Finalmente, el argumento anterior ha revelado el elemento dialéctico más fundamental en el multiculturalismo liberal. Aunque respeta una variedad de culturas, se niega a tomarlas en la estimación que ellas mismas se atribuyen. Tiene sus propias razones para respetar las culturas... En particular, el multiculturalismo insta al respeto por las culturas que no son en sí mismas culturas liberales (muy pocas lo son). Lo hace al mismo tiempo que impone la protección liberal de la libertad individual en tales culturas. Esto en sí mismo conlleva un conflicto con las mismas culturas que insta al gobierno a respetar. El conflicto es inevitable porque el multiculturalismo liberal reconoce y respeta aquellas culturas debido a que están al servicio de valores verdaderos, y en la medida en que lo hagan. Dado que su respeto por las culturas está condicionado y basado desde un punto de vista exterior a muchas de ellas, no resulta muy sorprendente que se encuentre en una difícil alianza con quienes apoyan dichas culturas, en ocasiones uniéndoseles en un frente común mientras que en otras se vuelven contra ellos para imponer ideales de tolerancia y de respeto mutuo, o para proteger a los miembros de las mismas culturas contra la opresión por parte de su propio grupo... (Raz, 2001, p. 198).

Con estas y otras discusiones sin zanjar se llega a un segundo momento del constitucionalismo multicultural que se abre a los aportes de distintos niveles y se configura y fortalece en temas centrales del debate nacional e internacional en particular en el tema de mayor trascendencia aportado por este constitucionalismo el del sujeto colectivo de derechos. 
Este modelo judicial polifónico o dialógico puede ser relevante para enfrentar las tensiones entre la defensa del universalismo de los derechos humanos y el reconocimiento del pluralismo cultural, ya que muestra que la unidad de los derechos humanos no debe ser concebida como un apriori lógico ligado a nociones metafísicas, como dios o la naturaleza humana, sino que debe ser fruto de un reconocimiento y diálogo entre las culturas. Por ello es que podría hablarse de la "uni-diver-salidad" de los derechos humanos, precisamente para defender la idea de que ellos deben ser pensados como un resultado progresivo de una comunicabilidad entre las diversas culturas, a través de la puesta en perspectiva y la relativización de las mismas, pero sin que ello implique el abandono de la posibilidad de la comprensión crítica de las mismas. La apertura hacia otras civilizaciones, para luego de oír y comprender sus razones y motivos, criticar algunos de sus elementos, no excluye sino que por el contrario es el presupuesto mismo para buscar acuerdos relativos con respecto a asuntos comunes (Uprimny, 1998, pág. 106).

El tercer momento el actual se podría identificar como el multiculturalismo con influencia andina derivado de las constituciones de los noventas y que pretende entronizarse en los avances institucionales y jurídicos del reciente debate latinoamericano de la interculturalidad en el siglo XXI.

Se destaca de esta tercera etapa la influencia del constitucionalismo colombiano en la región y en particular en Bolivia, prueba de ello es el Tribunal Constitucional Plurinacional de Bolivia TCPB donde en un ejercicio hermenéutico realizado recientemente afirma: el TCPB en el ejercicio del control plural de constitucionalidad, deberán analizarse en el marco de los siguientes parámetros de axiomaticidad proporcional y razonable propios del paradigma del vivir bien: a) armonía axiomática; b) decisión acorde con cosmovisión propia; c) ritualismos armónicos con procedimientos, normas tradicionalmente utilizados de acuerdo a la cosmovisión propia de cada nación y pueblo indígena originario campesina; y, d) Proporcionalidad y necesidad estricta. (Resolución 1422 de 2012 Tribunal Constitucional Plurinacional de Bolivia) 
Estos parámetros de axiomaticidad son propios del constitucionalismo colombiano, de hecho el Tribunal Plurinacional va más lejos pero ello son desarrollos del diálogo de tribunales y sus mutuas interinfluencias.

Sin embargo avanzar a un constitucionalismo común en Latinoamérica pasa por una trasformación epistémica y sobre todo asumir un tránsito a la interculturalidad en ello coincidimos con Walsh en su conceptualización acerca de la interculturalidad:

\begin{abstract}
Entender la interculturalidad como proceso y proyecto dirigido hacia la construcción de modos "otros" del poder, saber, ser y vivir, permite ir mucho más allá de los supuestos y manifestaciones actuales de la educación intercultural, la educación intercultural bilingüe o inclusive la filosofía intercultural. No es argumentar a partir de la simple relación entre grupos, prácticas o pensamientos culturales, por la incorporación de los tradicionalmente excluidos dentro de las estructuras (educativas, disciplinares o de pensamiento) existentes, o solamente a partir de la creación de programas "especiales" que permiten que la educación "normal" y "universal" sigua perpetuando prácticas y pensamientos racializados y excluyentes. Es señalar la necesidad a visibilizar, enfrentar y transformar las estructuras e instituciones que diferencialmente posicionan grupos, prácticas y pensamientos dentro de un orden y lógica que, a la vez y todavía, es racial, moderno-occidental y colonial... (2009, p. 138).
\end{abstract}

La propia autora hace una diferenciación entre lo multi y lo pluri:

De hecho, los términos multi, pluri e interculturalidad tienen genealogías y significados diferentes. Lo pluricultural y multicultural son términos descriptivos que sirven para caracterizar la situación diversa e indicar la existencia de múltiples culturas en un determinado lugar planteando así su reconocimiento, tolerancia y respeto. El «multi» tiene sus raíces en países occidentales, en un relativismo cultural que obvia la dimensión relacional y oculta la permanencia de desigualdades e inequidades sociales. Actualmente es de mayor uso global, orientando políticas estatales y transnacionales de inclusión dentro de un modelo de corte neoliberal que busca inclusión dentro del mercado. El «pluri», en 
cambio, es término de mayor uso en América del Sur; refleja la particularidad y realidad de la región donde pueblos indígenas y negros han convivido por siglos con blanco-mestizos y donde el mestizaje y la mezcla racial han jugado un papel significante. $(2008$, p. 141$)$.

Y es concluyente la autora al señalar que la interculturalidad no existe, este es un proyecto a construir:

La interculturalidad, en cambio, aún no existe. Es algo por construir. Va mucho más allá del respeto, la tolerancia y el reconocimiento de la diversidad; señala y alienta, más bien, un proceso y proyecto social político dirigido a la construcción de sociedades, relaciones y condiciones de vida nueva y distintas. Aquí me refiero no sólo a las condiciones económicas sino también a aquellas que tienen que ver con la cosmología de la vida en general, incluyendo los conocimientos y saberes, la memoria ancestral, y la relación con la madre naturaleza y la espiritualidad, entre otras. Por sí, parte del problema de las relaciones y condiciones históricas y actuales, de la dominación, exclusión, desigualdad e inequidad como también de la conflictividad que estas relaciones y condiciones engendran, es decir la «colonialidad»... (2008.141).

En el camino de consolidar una perspectiva multicultural se encuentran la mayor parte de los Estados y los sistemas jurídicos poco hacen para avanzar a una interculturalidad, en el siguiente aparte se revisan algunas de las tendencias del constitucionalismo en materia de pluralismo que corroboran que salvo la excepción mencionada los avances son poco alentadores en Latinoamérica.

\section{CONSTITUCIONALISMO Y PLURALISMO(S)}

En la perspectiva neo constitucional cabe plenamente el multiculturalismo como respuesta a los desafíos de la diversidad, los canonistas de este enfoque teórico reducen su mirada a la consagración "retórica" de derechos colectivos y a la incorporación de los tratados relevantes en el respectivo bloque constitucional. Los nuevos constitucionalismos 
avanzan sin socavar la hegemonía colonial del monismo y del fetiche legal, pero aportan elementos democráticos y valores comunitarios desconocidos por la tradición liberal, pero las dos perspectivas son insuficientes todavía para responder a las realidades culturales contemporáneas y a sus múltiples expresiones en Latinoamérica.

Lo que es evidente hoy son tres expresiones del pluralismo legal que podemos analizar, ellos son a saber: el pluralismo desconstitucionalizador, el pluralismo flexible y el pluralismo descolonizante.

\section{EL PLURALISMO DESCONSTITUCIONALIZADOR}

Este pluralismo es el realizado por todos los doctrinantes y teóricos que consideran vigente y pertinente el pensamiento europeo y norteamericano para resolver los problemas de las sociedades latinoamericanas desconociendo los aportes de la región en dicha materia, pero además niegan otras culturas y sociedades dentro del Estado, sin dejar de mencionar que todo lo logrado por las minorías es visto como una concesión del sistema hegemónico liberal dominante y no como una conquista después de años de lucha. Ven en perspectiva multicultural y niegan la posibilidad de una interpretación diferente sin tomar en cuenta las naciones o pueblos que piden otras comprensiones más cercanas a sus cosmovisiones.

El chileno José Aylwin expresa claramente la situación de su país que da cuenta en buena parte de este fenómeno:

"Los sectores conservadores niegan la pluralidad y están claramente representados en el pensamiento del Tribunal Constitucional, que ha interpretado en dos sentencias, en 2000 y 2008 , de manera altamente restrictiva las disposiciones del Convenio, por ejemplo al disponer que la consulta de los pueblos indígenas no es vinculante y al establecer que los derechos de participación de los pueblos indígenas en los planes de desarrollo son incompatibles con las formas de participación previstas en la Constitución o que los derechos al pluralismo jurídico o al derecho consuetudinario no son aplicables porque no son compatibles con la Carta Magna y que las normas correspondien- 
tes al derecho de propiedad de tierras y recursos tampoco son autoejecutables y requieren de reformas legales que, dada la naturaleza binominal del Congreso chileno, requerirían de otras dos décadas para viabilizarse."

Esta posición chilena es del monismo más recalcitrante y no puede ubicarse en nada distinto a lo ya señalado como negación de la pluralidad, existe un segundo fenómeno descontitucionalizante y es realizado por los neoconstitucionalistas que quieren preservar un lugar en la tradición liberal pero que pretenden llenar de contenido categorías nuevas propuestas por los nuevos constitucionalismos sin dejar de expresar sus preocupaciones por lo universal de ciertos derechos, la seguridad jurídica y los necesarios límites y subordinación de los otros sistemas normativos en el entendido de mantener el "orden" jurídico.

Son varios los neoconstitucionalistas que con la gramática nueva esconden su velo conservador/liberal y pretenden relegitimar el clásico modelo de monismo jurídico, ellos tiene un común denominador y es justificar todo su discurso monista en la protección de los derechos humanos y en la pretensión inequívoca del universalismo de estos, analizaremos un texto de reciente publicación en materia de pluralismo que nos permiten constatar los trazos de un discurso desconstitucionalizador (BAZÁN; NASH ROJAS, 2014).

Dentro del libro referenciado, el texto se denomina "Los pueblos indígenas originarios en el nuevo sistema constitucional boliviano" de Rivera S, señala

El primer reto que tiene la Jurisdicción Constitucional es el de
preservar y resguardar los mandatos de la Constitución y del
bloque de constitucionalidad, para materializar la integración de
los pueblos indígenas originarios a la estructura social, eco-
nómica, jurídica y política del Estado; en especial de aquellos
mandatos que constituyen obligaciones positivas que deben ser
cumplidas estrictamente por el Estado.

E insiste en la misma página 18 el autor "Sin duda alguna, la Constitución promulgada el 7 de febrero de 2009 presenta un buen diseño constitucional para lograr la integración material de los pueblos indí- 
genas originarios al sistema constitucional del Estado boliviano". Lo común en los dos párrafos del texto es nuestro subrayado, la categoría integración, que es efectivamente la acepción de incorporados subordinados al nuevo "derecho mayor" el del Estado constitucional.

Y continua su análisis:

Como una garantía de esa integración el Estado asegura a las naciones y pueblos indígenas originarios su libre determinación en el marco de la unidad nacional, que consiste en su derecho a la autonomía, al autogobierno, a su cultura, al reconocimiento de sus instituciones y a la consolidación de sus entidades territoriales, conforme a la Constitución y las leyes; así lo dispone expresamente el artículo $2^{\circ}$ de la Constitución.

Y además agrega el autor "Como manifestación de su integración plena a la estructura social del Estado, el artículo $3^{\circ}$ de la Constitución proclama que 'la nación boliviana está conformada por la totalidad de las bolivianas y los bolivianos, las naciones y pueblos indígena originario campesinos y las comunidades interculturales y afrobolivianas que en conjunto constituyen el pueblo boliviano'". Y como si fuera poco hace el siguiente comentario de matiz profundamente mono cultural: "Más allá de lo redundante que pueda suponer el texto de la norma constitucional referida, implica que las naciones y pueblos indígenas originarios forman parte de la estructura social boliviana".

Se necesitó esta reforma constitucional para integrarlos y además para que por fin formaran parte de la estructura social boliviana, pero el siguiente aparte es mucho más contundente en señalar el corte monucultural y monolegal del texto.

Remata con la siguiente referencia en la misma página 9:

De otro lado, el Estado boliviano reconoce y declara como sus idiomas oficiales los de las naciones y pueblos indígena originario campesinos, pues por mandato del artículo $5^{\circ}$ de la Ley Fundamental constituyen idiomas oficiales del Estado los 36 idiomas nombrados por la norma constitucional; aunque habrá de señalarse que muchos de ellos no componen propiamente un idioma sino un dialecto. 
Desafortunadamente el autor no aclara porque categoriza entre los 36 idiomas que algunos tienen la categoría de dialectos a la vieja usanza o si efectivamente es su carácter desconstitucionalizante.

Lo que no referenció en su texto José Antonio Rivera es la nueva forma interpretación constitucional que adopta el Tribunal constitucional y sus alcances en materia de pluralismo

El texto refleja su desconocimiento del tema del pluralismo indistintamente de sus carencias teóricas y de su poco revisión bibliográfica, el autor es muy evidente en su preocupación por mantener un estado de cosas (in) constitucional bajo presupuestos que aduce de pluralistas cuando sus reflexiones no alcanzan el modelo de pluralismo clásico bastante superado por la doctrina legal.

\section{EL PLURALISMO FLEXIBLE "PLURIPRIVACIDAD"}

Una tendencia que es muy fuerte en diferentes Estados es la de la privatización de la justicia y esto conlleva a una versión del pluralismo que para el presente análisis denominamos pluralismo flexible, pues se acomoda a las necesidades del mercado y es ofertado por particulares que fungen en calidad de ciudadanos que coadyuvan en la administración de justicia

Existe la pregunta de hasta qué punto el reconocimiento estatal del pluralismo legal encaja dentro de las tendencias generalizadas del Estado neoliberal de privatizar la ley y la justicia. En aquellos países donde el derecho consuetudinario indígena ha sido formalmente reconocido, en efecto se percibe a las prácticas legales indígenas como una forma alternativa de resolución de conflictos (ADR por sus siglas en inglés). Se puede argumentar que de esa manera el Estado neoliberal se desentiende de su responsabilidad central de garantizar el pacto de ciudadanía. En este escenario, el pluralismo legal se convierte en una decisión deliberada del Estado de abandonar ciertos espacios sociales y actores: en otras palabras, de deshacerse de las funciones tradicionales del Estado de coerción y protección que sostiene el pacto de una ciudadanía común. Esto permite que actores sociales particulares asuman estas funciones (SIEDER). 
Sea cual sea su denominación el pluralismo flexible se expresa de maneradiferentes conforme a las políticas públicas que más representen los intereses en juego como formas de justicia informal, masc, o formas de justicia comunitaria. Por virtud de la cooperación internacional la justicia indígena en las últimas décadas tiene importantes recursos en lógica de acomodarla al Estado de derecho y al discurso internacional de los derechos humanos.

Una expresión clara del pluralismo jurídico flexible, se encuentra en la justicia comunitaria, la cual está constituida por una serie de mecanismos tales como la conciliación en equidad y los jueces de paz, los cuales se originan en diversas comunidades que componen nuestros Estados y aunque en algunos casos se han ido integrando en el poder judicial del Estado, tienen la finalidad de ser alternativas más próximas al ciudadano, para que éste pueda resolver de manera más rápida sus conflictos. Coincidiendo con las lógica del mercado y de la eficiencia y eficacia social tan importante al modelo de justica privatista.

La segunda línea de pluralismo flexible es llevada al terreno de los derechos. Prácticamente todos estos temas entrañan problemas que se pueden traducir al lenguaje de derechos: derecho a administrar justicia, derecho a la autonomía, derecho al territorio, derecho a la consulta, derecho a la equidad de género, derecho a la salud, a la educación, a la seguridad, derechos de la infancia, derechos sexuales y reproductivos, etc. $Y$ en ese marco el multiculturalismo como expresión suprema de este tipo de pluralismo agota la posibilidad de avanzar a la interculturalidad frente a los cánones incuestionables de los derechos liberales fundamentales o incluso fundamentalísimos.

\section{PLURALISMO INTERCULTURAL DESCOLONIZANTE}

El camino para consolidar un pluralismo fuerte empieza por la realización de un Bloque Intercultural Jurídico (BIJ), la traducción intercultural y el informe propio de justicia propia. 
El BIJ es entendido como una armonización entre las normas internacionales, la constitución y los órdenes propios de los pueblos, comunidades indígenas y afrodescendientes. Es un apoyo intercultural descolonizador entendido como un conjunto de normas legislativas que permite una doble entrada para determinar la competencia de la Jurisdicción Especial Indígena: el auto-reconocimiento de los indígenas, y en segundo lugar la potestad de los pueblos de impartir justicia, con ello se brinda una integralidad básica para consolidar el respeto y protección de los derechos colectivos de los pueblos indígenas, el respeto y protección de los derechos individuales de las personas indígenas. Con ello la persona indígena puede acceder a la jurisdicción con tranquilidad con el fin de obtener pronta, específica y cumplida justicia. ${ }^{2}$

El fundamento se halla en la necesidad de los pueblos indígenas de que su derecho no sea vulnerado, y del sistema judicial en general de que no se paralice el servicio de justicia, por lo que la protección de la jurisdicción indígena protege el interés general y las normas internacionales junto con las de derecho propio ajustadas en armonía con la idea de descolonización jurídica y no subordinación de un orden jurídico a otro orden.

El BIJ contempla entonces un ejercicio de-construcción de los tratados internacionales, la Constitución vigente, la legislación nacional e indígena y por supuesto la ley de origen o el llamado derecho propio.

La forma de materializar el BIJ es sin duda la traducción intercultural, que se hará caso a caso, como la entiende Boaventura (2012, p. 147), un mecanismo de traducción intercultural que permite interpretar la Constitución y el Derecho Internacional de los Derechos Humanos en términos interculturales. En otros términos, los propios derechos fundamentales deben ser sometidos a interpretación intercultural. Los valores plasmados en esos derechos deben ser respetados, pero las actuaciones concretas que los respetan o que los violan, no siendo éticamente neutras, pueden ser objeto de interpretaciones opuestas conforme a las normas culturales de las que se parta 
Y el informe de justicia propia, al estilo de los realizados por la Unidad de descolonización del Tribunal Constitucional Plurinacional de Bolivia, con una conformación intercultural y el procedimiento que en estos dos años realiza esta unidad.

Lo desarrollado por la Unidad de Descolonización, aporta tres elementos novedosos, el primero es que el peritaje intercultural no lo hacen los científicos o cientistas sociales sino un grupo de sabedores y expertos de los diferentes sistemas de derecho, segundo que en dicho proceso participa la comunidad étnica involucrada y tercero que su validez no depende del método jurídico sino de la legitimidad socio cultural.

El alcance de este proceder de la Unidad de descolonización lo podemos auscultar en el Informe de la: comunidad indígena chiquitana altamira - la porfia, (municipio de concepción, provincia Ñuflo de Chavez, departamento de Santa Cruz) de noviembre de 2013.

El numeral uno del informe da cuenta de lo siguiente: Si efectivamente la referida comunidad cuenta con un sistema de administración de Justicia Indígena. Si la respuesta es afirmativa, se debe indagar sobre el modo de organización de su sistema de administración de Justicia Indígena.

El numeral dos de este informe se titula: Informen si el ejercicio de jurisdicción por parte de las naciones y pueblos indígenas originarios campesinos les resulta obligatoria, si se dan los supuestos del Art. 191.II de la C.P.E., o si la misma puede ser renunciable y en su caso precisar en qué situaciones, resulta igual para el presente análisis observar el numeral tres: De manera general y teórica informen cómo perciben el inter-relacionamiento y diálogo entre los sistemas de justicia en el Estado Plurinacional de Bolivia.

Respecto al numeral dos esto es lo que el informe señala: En la comunidad indígena originaria de Altamira, el ejercicio de la jurisdicción indígena originario campesino se aplica dentro de la jurisdicción territorial, en ámbitos de vigencia personal, material y territorial, conforme establece el Art. 191. II de la C. P. E. y la Ley No. 073 de Deslinde Jurisdiccional. Para las autoridades y comunarios de Altamira, la aplicación de la Justicia Indígena Originaria Campesina, no es obligatoria; en 
otros términos, no significa una obligación para los comunarios cumplir lo que establece el artículo mencionado. Ya que siempre las comunidades han practicado y aplicado desde sus ancestros las formas de resolución de conflictos. Por lo cual, las normas mencionadas no es una opción aparte, sino más bien está relacionado conforme a sus usos y costumbres, en relación señalan lo siguiente: "nosotros siempre hemos resuelto nuestros problemas en función de los usos y costumbres, para nosotros aunque no conocemos mucho lo que señala la Ley del deslinde en parte es lo que nosotros hacemos y siempre hemos resuelto nuestros problemas en función de los usos y costumbres". ${ }^{3}$ Por lo cual, la comunidad de Altamira antes de las reformas estructurales que ha cambiado la relación Estado - pueblos indígenas, en Altamira las familias han mantenido sus formas de resolución de conflictos basados en su cosmovisión propia.

En relación al numeral tres se dice lo siguiente: En relación al inter-relacionamiento y diálogo entre la Justica Indígena Originaria Campesina y la Justicia Ordinaria, dentro del Estado Plurinacional de Bolivia; se advierte que los habitantes de Altamira no ven una relación ni mecanismos de cooperación y coordinación entre ambas justicias. Contrariamente, desconocen las funciones y atribuciones de la Justicia Ordinaria, consideran como una instancia superior a su propia justicia. Según las autoridades y comunarios de Altamira señalan; “... Nosotros como autoridades de Altamira casi no acudimos a las autoridades de la justicia ordinaria, (...) sólo por los conflictos que tenemos con la familia del señor Carlos Bailaba, más antes no hemos tenido un conflicto similar...". En varios pasajes de la intervención de las autoridades de Altamira señalan que su sistema de justicia no está en condiciones de resolver los conflictos mayores.

Las razones por las que acudieron a la Justicia Constitucional, según las autoridades y comunarios de Altamira, es con el fin de lograr paralizar los constantes abusos y atropellos de Carlos Bailaba y su familia

3 Testimonio del señor corregidor Patricio Hurtado, corregidor de la comunidad de Altamira, 17/10/2013. 
en contra de la comunidad de Altamira, quienes han protagonizado una serie de agresiones de carácter verbal, o de inasistencia a reuniones, rechazo a las autoridades en perjuicio de toda la comunidad. El proyecto de desarrollo apoya por el programa Pro Tierra, es uno de los factores del conflicto que confrontó entre los comunarios de Altamira y la familia de Carlos Bailaba Mangarí. Los intentos de solución que se dieron en la propia comunidad no tuvieron un alcance favorable a una solución del conflicto, situación por el cual, o ante el fracaso de una solución en la propia comunidad, las autoridades y comunarios de Altamira acuden a la Justicia Constitucional para encontrar una solución favorable a la comunidad, a todos las familias que forman parte de la comunidad de Altamira. (Informe Unidad de descolonización página 35).

En las conclusiones el informe deja establecido los siguiente: Cómo se ha indicado en los contenidos del presente documento, la comunidad sólo tienen conocimiento de la forma como sus autoridades imparten justicia, ya que también, la propia comunidad es responsable de las sanciones que se determinan en una asamblea comunitaria; en ese sentido, existe una percepción positiva de las bases o comunarios sobre el rol de sus autoridades, siempre y cuando son asuntos que incumben a su competencia; en ese caso, deciden en una asamblea comunitaria. La comunidad de Altamira tiene dos tipos de reunión, una asamblea comunitaria ordinaria que lleva adelante una vez al mes, otra asamblea comunitaria extra-ordinaria que se convoca en momentos de emergencia. En relación a la fiscalía, justicia ordinaria, constitucional, son entidades que la propia comunidad desconoce su rol o función; por tanto, desconocen si éstas son eficaces o ineficaces, (en varios pasajes de la reunión se han referido sólo a la fiscalía, que llegaron a conocer por el conflicto que tienen con la familia de José Bailaba).

Este informe coadyuva a la decisión que el Tribunal Constitucional Plurinacional toma respecto a esta materia puesto a su conocimiento, y sin duda avanza en lo que el modelo jurídico conocía a la fecha como peritaje cultural.

Los elementos aportadas por la propia comunidad adquieren relevancia en un sistema que procura avanzar a la interculturalidad y no quedarse en el mero "formalismo". 


\section{CAMINOS Y POSIBILIDADES DEL PLURALISMO INTERCULTURAL}

En común en América Latina tenemos un alto déficit pluralista ello conlleva a distintos desarrollos de la pluralidad jurídica en los países de la región.

Las diferencias actuales saltan a la luz, Chile aparece como el caso paradigmático del lento avance formal y del débil reconocimiento constitucional del pluralismo. En cambio, en Ecuador y Bolivia las nuevas Constituciones parecerían garantizar los derechos que se han incluido en ellas como efecto de la emergencia de un "pluralismo desde abajo" que ha resultado efectivo en términos del reconocimiento de los derechos de los sectores marginados y excluidos, notoriamente los pueblos indígenas. Aquí la cuestión central es el desafío de cómo articular eficazmente el mandato constitucional con el ordenamiento jurídico vigente o por reconfigurarse (GTZ, 2010).

Una doctrina orientada a sistemas jurídicos plurales debe caminar la ruta que propone el constitucionalismo boliviano el de la interculturalidad, en esta propuesta hay varios aportes que revisar para lograr un avance común en este momento primordial en Latinoamérica.

...a partir de la concepción del pluralismo como elemento fundante del Estado, el modelo de Estado, se estructura sobre la base de derechos individuales y también derechos con incidencia colectiva, pero además, la concepción del pluralismo y la interculturalidad, configuran un diseño de valores plurales rectores destinados a consolidar el vivir bien, en ese orden y al abrigo de la estructura axiomática plasmada en el Preámbulo de la Constitución la interculturalidad, asegura que los valores plurales supremos, se complementen en una sociedad plural e irradien de contenido todos los actos de la vida social, incluidos aquellos procedimientos o decisiones emanadas de los pueblos y naciones indígenas originarios campesinos. (Resolución 1422 de 2012 Tribunal Constitucional Plurinacional de Bolivia). 
Pero nuevamente el Tribunal Constitucional Plurinacional va más allá que cualquier Estado en Latinoamérica al señalar de manera taxativa lo siguiente:

...es imperante establecer que el pluralismo jurídico, genera como efecto en el modelo de Estado, la consagración de un pluralismo de fuentes jurídicas, aspecto que implica la superación del Estado Monista; en este orden, en mérito a este aspecto, se tiene que el orden jurídico imperante en el Estado Plurinacional de Bolivia está conformado por dos elementos esenciales: 1) La Constitución como primera fuente directa de derecho; y, 2) las normas y procedimientos de las naciones y pueblos indígena originario campesinos, también como fuente directa de derecho. (Resolución 1422 de 2012 Tribunal Constitucional Plurinacional de Bolivia)

Sin duda alguna esta es la ruptura más protuberante que hace el Tribunal Plurinacional retomada de la constitución Boliviana y hace que efectivamente se posibilite un pluralismo intercultural dado por el numeral dos que reconoce explícitamente como fuente de derecho las normas y procedimientos de las naciones y pueblos originarios campesinos, en términos concretos esto es lo mas avanzado en materia de pluralismo que se ha logrado en Latinoamérica en muchos Estado están lejos de comprender que un ejercicio de interculturalidad obliga a romper la clásica idea de la fuentes del derecho e incluir otros sistemas jurídicos.

Y en esta misma resolución 1422 concluye el Tribunal Boliviano:

...del test del paradigma del vivir bien, utilizará el método jurídico de la ponderación intercultural, a cuyo efecto, a la luz de los valores plurales supremos antes descritos, deberá cotejar los fines perseguidos por la decisión en relación a los medios empleados, para luego verificar la armonía de los fines y medios utilizados en la decisión con los valores plurales supremos descritos precedentemente, evitando así una discordancia con los postulados de la Constitución axiomática.

La Constitución boliviana además de la ya señalado ha diseñado un sistema de control de constitucionalidad plural, pues no solamente se 
ejerce el control sobre normas formales, sino también sobre las normas de las naciones y pueblos indígena originario campesinos, además de conocer los conflictos de competencias entre las diferentes jurisdicciones y de revisar las resoluciones pronunciadas por la jurisdicción indígena originaria campesina cuando se considere que estas normas son lesivas a los derechos fundamentales y garantías constitucionales.

Estas facultades fueron introducidas en la actual Constitución Política del Estado, en mérito al reconocimiento expreso a los derechos de los pueblos indígenas originario campesinos, a la igualdad jerárquica de sistemas jurídicos y jurisdicciones; pero además debe considerarse que la Ley Fundamental fue el resultado de un proceso dialógico en el que intervinieron los diferentes sectores de la población boliviana y, claro está, también las naciones y pueblos indígena originario campesinos, que tuvieron un rol protagónico para la consolidación del Estado Plurinacional

Y no se puede dejar de mencionar la constitucionalidad del primer estatuto autonómico que se hizo en la declaración constitucional plurinacional 0009/2013 Sucre, 27 de junio de 2013, en ella en el numeral III.2. de la Naturaleza, alcances y acceso a la autonomía indígena el Tribunal señala: La autonomía indígena originario campesina adquiere características singulares y propias, puesto que es la manifestación institucional de una realidad indígena por largo tiempo postergada y alejada del acceso al poder político formal, adquiriendo por esta razón un carácter emancipatorio y liberador.

Agrega el Tribunal: Se constituye, como reza el preámbulo constitucional, en un componente sustancial del proceso de construcción de una nueva estatalidad basada en la pluralidad "...económica, social, jurídica, política y cultural de los habitantes de esta tierra" y en la libre determinación de las naciones y pueblos indígena originario campesinos como una forma de reconocimiento a su existencia precolonial y el dominio ancestral sobre sus territorios, reconociéndosele, en el marco de la unidad del Estado, su derecho a la autonomía, al autogobierno, a su cultura, al reconocimiento de sus instituciones y a la consolidación de sus entidades territoriales, conforme a esta Constitución y la ley, como se expresa textualmente en el art. 2 constitucional. 
Este reconocimiento demuestra el alcance de la pluralidad en Bolivia y su materialización con lo señalado hasta aquí es posible pensar que otro derecho es posible y que el camino de la descolonización jurídica está en marcha.

\section{BIBLIOGRAFÍA}

ARIZA SANTAMARÍA, Rosembert (2010) El derecho Profano y de otras maneras de realizar lo justo, Universidad Externado de Colombia.

BAZÁN, Víctor; NASH ROJAS, Claudio (2014) Justicia constitucional y derechos fundamentales. $N^{\circ} 4$. Pluralismo jurídico, Bogotá: Editorial Universidad del Rosario, Facultad de Jurisprudencia, 2014. (Colección Textos de Jurisprudencia).

CHIVI, Vargas, Idón Moisés (2009). Los caminos de la descolonización por América Latina: Jurisdicción Indígena Originaria Campesina y el Igualitarismo Plurinacional Comunitario en: https://www.unifr.ch/ ddp1/derechopenal/articulos/a_20090505_01.pdf

GARCÍA LINERA, Álvaro; Prada Raúl, Tapia Luis, Vega Oscar (2010). El Estado. Campo de lucha, La muela del Diablo, La Paz, Bolivia.

GTZ (2010). La transformación de la juridicidad en los estados latinoamericanos: efectos del pluralismo jurídico desde arriba y desde abajo sobre el Estado de derecho. Bogotá: Arko. Ver en: http://www2.gtz.de/ dokumente/bib-2010/gtz2010-0372es-efectos-pluralismo-juridico.pdf

MARTÍNEZ, Juan Carlos; STEINER, Christian; URIBE, Patricia; MASELLI, Claudia (coords.) (2012). Elementos y técnicas de pluralismo jurídico: manual para operadores de justicia. Grupo por el Pluralismo Jurídico Prujula y KAS.

SOUSA SANTOS, Boaventura (2012). Cuando lo excluidos tienen derecho. En Justicia indígena Plurinacionalidad e interculturalidad en Ecuador Fundación Rosa Luxemburg, Aby Ayala, Quito Ecuador.

SIEDER, Rachel. Pluralismo legal y globalización jurídica: retos Del Multiculturalismo En América Latina. Ver en :http://www.ibcperu.org/ doc/isis/12997.pdf 
SIERRA, Marie Teresa; HERNANDEZ, Rosalva; SIEDER, Rachel (2013). Justicias indígenas y Estado, violencias contemporáneas, FLCASO; CIESAS, México.

WOLKMER, Antonio Carlos; CORREAS, Oscar (Org.) (2013). Crítica Jurídica na América Latina. Aguascalientes: CENEJUS, México.

Artigo enviado e aceito em fevereiro de 2015. 